\title{
Bevacizumab induced intestinal perforation in patients with colorectal cancer
}

Sun Young Baek, Seung Hun Lee, Seung Hyun Lee

Department of Surgery, Kosin University College of Medicine, Busan, Korea

Purpose: Bevacizumab has been used as a promising drug for metastatic colorectal cancer in combination with chemotherapeutic agents. However, it has a few serious adverse effects, such as intestinal bleeding or perforation. The purpose of this study is to identify the clinical characteristics of intestinal perforation induced by bevacizumab in colorectal cancer patients.

Methods: From January 2007 to June 2018, a total of 488 patients underwent chemotherapy with bevacizumab for metastatic colorectal cancer. Medical records were reviewed retrospectively.

Results: Nine patients (1.8\%) were identified with intestinal perforation induced with bevacizumab. The median age was 59 years (range, 36-68 years). The primary tumor site was the sigmoid colon in six patients, the rectum in three patients. The liver was the most common metastatic organ (7 patients). Perforation sites were primary tumor site of the colorectum in four patients and the small bowel in five patients. Intestinal perforation was developed after a median of 3 chemotherapy cycles (range, 1-15 cycles), and a median of 7 days (range, 3-32 days) after chemotherapy. One patient expired due to sepsis.

Conclusion: Bevacizumab induced intestinal perforation is a lethal adverse effect in patients with colorectal cancers. The characteristics of intestinal perforation varied according to perforation site, previous chemotherapy cycles, and clinical course. Careful monitoring is necessary with the use of bevacizumab in conjunction with chemotherapeutic agents.

Keywords: Colorectal neoplasms, Tumor, Intestinal perforation, Bevacizumab

\section{INTRODUCTION}

Bevacizumab, a recombinant humanized monoclonal antibody targeting vascular endothelial growth factor, is an antiangiogenic agent approved for the treatment of multiple solid tumors. It has shown promise as a clinical agent against metastatic colorectal cancer, and particularly in combination with chemotherapy [1]. With increased use of bevacizumab, serious adverse effects are being reported more frequently, including hypertension, proteinuria, hem-

Received: Feb 18, 2019 Revised: Jun 10, 2019 Accepted: Jun 11, 2019 Correspondence to: Seung Hyun Lee

Department of Surgery, Kosin University College of Medicine,

262 Gamcheon-ro, Seo-gu, Busan 49267, Korea

Tel: +82-51-990-6462, Fax: +82-51-246-6093

E-mail: gscrslsh@hanmail.net

ORCID: Sun Young Baek (https://orcid.org/0000-0002-3327-5938), Seung Hun Lee (https://orcid.org/0000-0001-9041-3156), Seung Hyun Lee (https://orcid.org/00000002-5610-5237)

Copyright (C) 2019 Korean Society of Surgical Oncology

This is an Open Access article distributed under the terms of the Creative Commons Attribution Non-Commercial License (http://creativecommons.org/licenses/by-nc/4.0) which permits unrestricted non-commercial use, distribution, and reproduction in any medium, provided the original work is properly cited. orrhage, thrombosis, fistula formation, and bowel perforation [24]. In two phase 3 trials of bevacizumab in colorectal cancer, intestinal perforation was an uncommon adverse event occurring at rates of only $1.5 \%$ and $1.1 \%$, though serious and lethal. Here, the purpose of this study is to identify the clinical characteristics of intestinal perforation induced by bevacizumab in colorectal cancers.

\section{METHODS}

From January 2007 to June 2018, a total of 488 patients underwent chemotherapy with bevacizumab (Avastin, Genentech, Inc., South San Francisco, CA, USA) with metastatic colorectal cancers. Medical records were reviewed retrospectively. The study was approved by the Institutional Review Board of Kosin University Gospel Hospital (IRB 2019-01-013) and performed in accordance with the principles of the Declaration of Helsinki.

The use of chemotherapy was applied in patients younger than 75 years of age and having appropriate bone marrow, liver, and renal function (hemoglobin $>10 \mathrm{~g} / \mathrm{dL}$, leukocyte count $>4,000$ / $\mathrm{mm}^{3}$, platelets $>100,000 / \mathrm{mm}^{3}$, bilirubin $<2.0 \mathrm{mg}$, aspartate transaminase/alanine transaminase $<1.25$ normal value, creatinine 
$<1.25 \times$ normal value). The activity level was applied to patients with 0 to 2 using Eastern Cooperative Oncology Group criteria.

Bevacizumab was administered by intravenous infusion at 5 $\mathrm{mg} / \mathrm{kg}$ in combination with irinotecan (FOLFIRI) at $130-180 \mathrm{mg} /$ $\mathrm{m}^{2}$ by 2 -hour infusion with 5 -fluorouracil at $400 \mathrm{mg} / \mathrm{m}^{2}$ by bolus infusion followed by $600 \mathrm{mg} / \mathrm{m}^{2}$ continuous infusion for 22 hours, and with leucovorin at $20 \mathrm{mg} / \mathrm{m}^{2}$, every 2 weeks. With a FOLFOX regimen, bevacizumab was administered with oxaliplatin (FOLF$\mathrm{OX}$ ) at $85 \mathrm{mg} / \mathrm{m}^{2}$ by 2-hour infusion with 5 -fluorouracil at 400 $\mathrm{mg} / \mathrm{m}^{2}$ by bolus infusion followed by $600 \mathrm{mg} / \mathrm{m}^{2}$ continuous infusion for 22 hours, and with leucovorin at $20 \mathrm{mg} / \mathrm{m}^{2}$.

For the patients with intestinal perforation induced by bevacizumab, clinical characteristics were reviewed such as perforation sites, surgery of intestinal perforation, postoperative complication, chemotherapy cycles, and interval between chemotherapy and intestinal perforation.

\section{RESULTS}

Of the 488 patients, nine patients (1.8\%) were identified with intestinal perforation induced by bevacizumab. The median age was 59 years (range, 36-68 years). Primary tumor site was the sigmoid colon in six patients, the rectum in three patients. The liver was the most common metastatic organ in seven patients. Six patients un-

Table 1. Characteristics of bevacizumab induced intestinal perforation in colorectal cancer

\begin{tabular}{lc}
\hline Characteristic & Patients $(\mathrm{n}=9)$ \\
\hline Sex (male:female) & $6: 3$ \\
Age (yr) & $59(36-68)$ \\
Primary tumor site (colon:rectum) & $6: 3$ \\
Metastasis site & \\
$\quad$ Liver & 7 \\
Lung & 1 \\
Peritoneum & 3 \\
Ovary & 1 \\
Resection of primary tumors (yes:no) & $6: 3$ \\
Perforation site (small bowel:colorectum) & \\
Perforation at primary tumor sites & $5: 4$ \\
Concurrent chemotherapy regimen & 3 \\
FOLFOX & \\
FOLFIRI & 4 \\
Bevacizumab, total use (cycle) & 5 \\
Interval between chemotherapy and perforation (day) & $7(3-32)$ \\
Previous history of intestinal obstruction (yes:no) & $4: 5$ \\
\hline
\end{tabular}

Values are presented as median (range).

a) Low anterior resection in 5 cases, sigmoidectomy in 1 case, colostomy in 1 case. ${ }^{b}$ The jejunum in 3 cases, the ileum in 2 cases, the sigmoid colon in 2 cases, the rectum in 1 case and anastomotic site in the rectum in 1 case. derwent resection of primary tumor. Perforation sites were the colorectum in four patients, the small bowel in five patients ( 3 in the jejunum and 2 in the ileum). Primary tumor site perforation was in three patients. Intestinal perforation developed after a median of three chemotherapy cycles (range, $1-15$ cycles; $3-4$ cycles in 4 patients), and a median of 7 days (range, 3-32 days) after chemotherapy. Chemotherapy with bevacizumab was 3 rd line in case 1 and 2 nd line in case 8 . Stoma formation was done in six patients (Table 1). Postoperative complications were anastomotic leakage in one patient, paralytic ileus in two patients. One patient expired due to sepsis.

In one patient, two events of intestinal perforation developed at 3-month intervals. There was no chemotherapy after the first event of intestinal perforation. The 2 nd event of a colo-vesical fistula at the sigmoid colon developed. Hartmann's procedure and omentopexy were performed. The colo-vesical fistula developed after a total of 11 cycles of chemotherapy (FOLFIR) with bevacizumab, 134 days after chemotherapy.

\section{DISCUSSION}

For bevacizumab induced intestinal perforation, the commonly suggested predisposing factors are peptic ulcer disease, diverticulitis, chemotherapy-induced colitis, a history of abdominal radiation, abdominal carcinomatosis and bowel obstruction [5-7]. Saif et al. [8] observed that the incidence of intestinal perforation seemed to be higher in patients with intact primary tumors, a recent history of sigmoidoscopy or colonoscopy, or previous adjuvant radiotherapy. The reported locations of perforation have included the stomach, small bowel and large bowel $[3,4,7,9]$. The large bowel is the most common site of bowel perforation after bevacizumab combination chemotherapy. In this study, perforation sites were the colorectum in four patients, the small bowel in five patients. Primary tumor site perforation was in three patients. Four patients had preoperative intestinal obstruction.

The pathophysiologic mechanism by which bevacizumab leads to bowel perforation is unknown. There are several possible mechanisms [10]. One possibility is that the perforations are tumor-related. In this case, subsequent chemotherapy with bevacizumab may lead to necrosis of the tumor in the bowel serosa and thus predispose the patient to developing bowel perforation. Another possibility is that bevacizumab could limit blood flow to the splanchnic vasculature via thrombosis or vasoconstriction. A marginal blood supply to an area of the bowel could potentially lead to bowel infarction and then perforation. Finally, delayed wound healing with bevacizumab may result in leakage from the anastomotic site after bowel operation. In this study, perforation sites 
were the colorectum in four patients and the small bowel in five patients. Primary tumor site perforation was in three patients. In those cases, we assumed that tumor necrosis produced the intestinal perforation. Although the pathogenesis of the patient's intestinal perforation was not entirely understood, intestinal obstruction may be considered as the predisposing factor for bevacizumab-in- duced intestinal perforation.

Scappaticci et al. [5] suggested that the use of bevacizumab within 28 days of operation could increase the risk of wound healing complications after primary cancer surgery in colorectal cancer patients. In this study, there was no intestinal perforation as wound healing complication. In this study, intestinal perforation was de-

Table 2. Case review of small bowel perforation induced with bevacizumab

\begin{tabular}{|c|c|c|c|c|c|}
\hline Characteristic & Case 1 & Case 2 & Case 3 & Case 4 & Case 5 \\
\hline Sex & Female & Male & Male & Male & Male \\
\hline Age (yr) & 48 & 68 & 36 & 67 & 65 \\
\hline Primary tumor locations & Sigmoid colon & Rectum & Rectum & Sigmoid colon & Sigmoid colon \\
\hline Metastasis sites & Ovary, peritoneum & Liver, peritoneum & Liver & Liver & Liver \\
\hline Surgery for primary tumor & $\begin{array}{l}\text { Sigmoid colon } \\
\text { resection }\end{array}$ & LAR & LAR & LAR & LAR \\
\hline Perforation sites & lleum & Jejunum & Ileum & Jejunum & Jejunum \\
\hline Perforation at tumor sites & No & No & No & No & Yes \\
\hline Perforation surgery & $\begin{array}{l}\text { Small bowel resection } \\
\text { \& ileostomy }\end{array}$ & $\begin{array}{c}\text { Primary closure \& } \\
\text { jejunum ostomy }\end{array}$ & $\begin{array}{l}\text { Small bowel resection } \\
\text { \& ileostomy }\end{array}$ & $\begin{array}{l}\text { Small bowel } \\
\text { resection }\end{array}$ & $\begin{array}{l}\text { Small bowel } \\
\text { resection }\end{array}$ \\
\hline Postoperative complications & None & Expired & None & Leakage & None \\
\hline $\begin{array}{l}\text { Bevacizumab concurrent } \\
\text { chemotherapy regimen }\end{array}$ & FOLFOX & FOLFIRI & FOLFOX & FOLFIRI & FOLFIRI \\
\hline Bevacizumab, total use (cycle) & 1 & 4 & 3 & 11 & 3 \\
\hline $\begin{array}{l}\text { Interval between chemotherapy } \\
\text { and perforation (day) }\end{array}$ & 7 & 3 & 4 & 32 & 11 \\
\hline $\begin{array}{l}\text { Previous history of intestinal } \\
\text { obstruction }\end{array}$ & No & No & No & No & Yes \\
\hline Preoperative CEA & 854.3 & 2,476 & 6.2 & 5.2 & 4.2 \\
\hline
\end{tabular}

LAR, low anterior resection; CEA, carcinoembryonic antigen.

Table 3. Case review of the colorectum perforation induced with bevacizumab

\begin{tabular}{|c|c|c|c|c|}
\hline Characteristic & Case 6 & Case 7 & Case 8 & Case 9 \\
\hline Sex & Male & Female & Male & Female \\
\hline Age (yr) & 46 & 59 & 59 & 41 \\
\hline Primary tumor locations & Rectum & Sigmoid colon & Rectum & Sigmoid colon \\
\hline Metastasis sites & Liver & Peritoneum & Liver, lung & Liver \\
\hline Surgery for primary tumor & None & Colostomy & LAR & None \\
\hline Perforation sites & Rectum & Sigmoid colon & Rectum & Sigmoid colon \\
\hline Perforation at tumor sites & Yes & Yes & $\mathrm{No}^{\mathrm{a})}$ & Yes \\
\hline Perforation surgery & $\begin{array}{l}\text { Hartmann's } \\
\text { colostomy }\end{array}$ & $\begin{array}{c}\text { Peritoneal irrigation \& } \\
\text { drainage }\end{array}$ & lleostomy & $\begin{array}{c}\text { Sigmoid colon resection } \\
\text { \& ileostomy }\end{array}$ \\
\hline Postoperative complications & Paralytic ileus & Paralytic ileus & None & None \\
\hline Concurrent chemotherapy regimen & FOLFIRI & FOLFOX & FOLFOX & FOLFIRI \\
\hline Bevacizumab, total use (cycle) & 2 & 14 & 15 & 3 \\
\hline Interval between chemotherapy and perforation & 25 & 7 & 20 & 4 \\
\hline Previous history of intestinal obstruction & Yes & Yes & No & Yes \\
\hline Preoperative CEA & 1,082 & 6.8 & 12.8 & 12.4 \\
\hline
\end{tabular}

$L A R$, low anterior resection; CEA, carcinoembryonic antigen.

a) Rectum perforation at proximal site from the tumor site. 
veloped with a median of three chemotherapy cycles (range, 1-15 cycles; $3-4$ cycles in 4 patients) and a median of 7 days (range, 3-32 days) after chemotherapy (Tables 2 and 3).

In conclusion, intestinal perforation induced bevacizumab is uncommon, though a serious and fatal adverse effect. Although the pathophysiology is not completely understood, careful observation is imperative for those patients who are administered bevacizumab in combination chemotherapy. Awareness of signs and symptoms of peritonitis with abdominal pain, nausea, and vomiting is necessary, especially after $3-4$ cycles and within 7-10 days after bevacizumab administration. If intestinal perforation is diagnosed, bevacizumab administration should be ceased immediately and then resuscitation and early surgical intervention should be undertaken.

\section{CONFLICT OF INTEREST}

No potential conflict of interest relevant to this article was reported.

\section{REFERENCES}

1. Presta LG, Chen H, O'Connor SJ, Chisholm V, Meng YG, Krummen $\mathrm{L}$, et al. Humanization of an anti-vascular endothelial growth factor monoclonal antibody for the therapy of solid tumors and other disorders. Cancer Res 1997;57:4593-9.

2. Kabbinavar F, Hurwitz HI, Fehrenbacher L, Meropol NJ, Novotny WF, Lieberman G, et al. Phase II, randomized trial comparing bevacizumab plus fluorouracil (FU)/leucovorin (LV) with FU/LV alone in patients with metastatic colorectal cancer. J Clin Oncol
2003;21:60-5.

3. Giantonio BJ, Catalano PJ, Meropol NJ, O'Dwyer PJ, Mitchell EP, Alberts SR, et al. Bevacizumab in combination with oxaliplatin, fluorouracil, and leucovorin (FOLFOX4) for previously treated metastatic colorectal cancer: results from the Eastern Cooperative Oncology Group Study E3200. J Clin Oncol 2007;25:1539-44.

4. Hurwitz H, Fehrenbacher L, Novotny W, Cartwright T, Hainsworth J, Heim W, et al. Bevacizumab plus irinotecan, fluorouracil, and leucovorin for metastatic colorectal cancer. N Engl J Med 2004; 350:2335-42.

5. Scappaticci FA, Fehrenbacher L, Cartwright T, Hainsworth JD, Heim W, Berlin J, et al. Surgical wound healing complications in metastatic colorectal cancer patients treated with bevacizumab. J Surg Oncol 2005;91:173-80.

6. Gordon MS, Cunningham D. Managing patients treated with bevacizumab combination therapy. Oncology 2005;69 Suppl 3:25-33.

7. Lordick F, Geinitz H, Theisen J, Sendler A, Sarbia M. Increased risk of ischemic bowel complications during treatment with bevacizumab after pelvic irradiation: report of three cases. Int J Radiat Oncol Biol Phys 2006;64:1295-8.

8. Saif MW, Elfiky A, Salem RR. Gastrointestinal perforation due to bevacizumab in colorectal cancer. Ann Surg Oncol 2007;14:18609.

9. Heinzerling JH, Huerta S. Bowel perforation from bevacizumab for the treatment of metastatic colon cancer: incidence, etiology, and management. Curr Surg 2006;63:334-7.

10. Han ES, Monk BJ. What is the risk of bowel perforation associated with bevacizumab therapy in ovarian cancer? Gynecol Oncol 2007;105:3-6. 